\title{
Activation of Complement Alternative Pathway in Rheumatoid Arthritis: Implications in Peripheral Neutrophils Functions
}

\author{
A.B. Paoliello-Paschoalato a , M.R. Moreira ${ }^{\text {c, A.E.C.S. Azzolini }}{ }^{\mathrm{a}}$, Amarildo A. Cavenaghi ${ }^{\mathrm{a}}$, \\ C.M. Marzocchi-Machado ${ }^{\text {, }}$, E.A. Donadi ${ }^{\text {, }}$ A.I. Assis-Pandochi ${ }^{\text {a }}$ and Y.M. Lucisano-Valim*,
}

\author{
${ }^{a}$ Departamento de Física e Química, Faculdade de Ciências Farmacêuticas de Ribeirão Preto da Universidade de São \\ Paulo. Av. Café s/n., Ribeirão Preto - SP, 14040-903, Brazil \\ ${ }^{b}$ Departamento de Análises Clínicas, Toxicológicas e Bromatológicas, Faculdade de Ciências Farmacêuticas de \\ Ribeirão Preto da Universidade de São Paulo. Av. Café s/n., Monte Alegre, Ribeirão Preto, SP, 14040-903, Brazil \\ ${ }^{c}$ Departamento de Bioquímica e Imunologia, Faculdade de Medicina de Ribeirão Preto da Universidade de São Paulo. \\ Av. Bandeirantes 2900, Monte Alegre, Ribeirão Preto, SP, 14049-900, Brazil \\ ${ }^{d}$ Departamento de Clínica Médica, Faculdade de Medicina de Ribeirão Preto da Universidade de São Paulo. Av. \\ Bandeirantes 2900, Monte Alegre, Ribeirão Preto, SP, 14049-900, Brazil
}

\begin{abstract}
Evaluation of the respiratory burst induced by receptors Fc $\gamma \mathrm{R}$ and CR was carried out in peripheral blood neutrophils (PBN) in rheumatoid arthritis (RA) patients with active and inactive disease. Simultaneously, cooperation between these receptors and their expression, PBN chemotaxis, and complement system systemic activity were also investigated. Neutrophils were stimulated with IC-IgG opsonized with normal human serum (NHS) or not, or with IC-IgG opsonized with RA human serum (RAHS). ROS production was increased in neutrophils of patients with active or inactive RA stimulated of IC-IgG opsonized with NHS compared to the response of the cells mediated by ICIgG. However, there was poor FcyR/CR cooperation in these RA neutrophils, as indicated by decreased ROS production upon stimulation with IC-IgG opsonized with RAHS. In the case of active RA patients, neutrophils presented significantly higher CR1 and CR3 expression, as well as slight elevation in CD32 and CD16 expression. Positive correlations between Fc $\gamma \mathrm{R}$ and CR, complement alternative pathway activation, and increased RA serum chemotaxic activity were only detected in active RA patients. Taken together, these results indicate that several abnormalities of the complement system exist at the systemic level, namely impaired membrane receptor cooperation, alternative pathway activation, and presence of pre-existing chemoattractant factors in the serum, as reflected by the neutrophil function in the particular case of active RA patients. All, these abnormalities may synergistically contribute to RA pathogenesis.
\end{abstract}

Keywords: Neutrophils, rheumatoid arthritis, oxidative stress, Fc-gamma and CR receptors, complement system.

\section{INTRODUCTION}

Rheumatoid arthritis (RA) is a chronic immune inflammatory disease characterized by synovial hyperplasia, joint destruction, and extra-articular manifestations, which have significant impact on both morbidity and mortality. Although the etiopathology of this condition is not fully understood, it is known that neutrophils are proeminent participants in the joint inflammation detected in RA patients $[1,2]$.

Neutrophils migrate to the synovial fluid (SF), where they phagocyte immune complexes and release proteolytic enzymes and induce respiratory burst [3]. As a consequence, highly reactive oxygen species (ROS) such as superoxide $\left(\mathrm{O}^{-2}\right)$, hydrogen peroxide, and hypochlorous acid are produced $[4,5]$. ROS production by RA patients' neutrophils in the SF and tissues causes oxidative damage to hyaluronic acid [4] and low-density lipid proteins [6], which culminates

*Address correspondence to this author at the Departamento de Física e Química, Faculdade de Ciências Farmacêuticas de Ribeirão Preto da Universidade de São Paulo. Av. Café s/n., Ribeirão Preto - SP, CEP 14040-903, Brazil; Tel: 55-16-36024434; Fax: 55-16-36024880; E-mail: yaluva@usp.br in cartilage, extracellular collagen, and DNA damage [7]. Some investigators have suggested that PBN, as well as neutrophils from RA patients' SF are activated. Elevated numbers of low-density neutrophils have been found in RA patients' venous blood [8]. Ultrastructural examination of neutrophils purified from RA patients' blood has revealed that these cells are more often polarized (non-spherical) compared to neutrophils derived from normal subjects [9]. These changes are similar to those experienced by normal neutrophils activated by exposure to bacteria, chemoattractants, or complexes containing rheumatoid factors, suggesting that they reflect cell activation $[10,11]$.

ROS generation modulates adhesion molecules and neutrophil receptors expression [12]. Neutrophil oxidative burst is initiated by interaction of cell-surface complement (CR) and immunoglobulin $\mathrm{G}(\mathrm{Fc} \gamma \mathrm{R})$ receptors with immune complexes (ICs) [13]. The major CR1 (CD35) ligands are C3b, C4b [14], and C3bi, with lower affinity [15], whereas C3bi is the main CR3 (CD11b/CD18) ligand [16]. Both CR1 and CR3 are implicated in the phagocytosis of complementopsonized particles [17]. C3b and its degradation product C3bi interact with complement receptors and activate im- 
mune complex phagocytosis by $\mathrm{CR} 1$ and CR3, normally present in SF neutrophils [12]. As for Fc $\gamma \mathrm{R}$, three classes of ligands have been described for this leukocyte: Fc $\gamma$ RI (CD64), which binds to monomeric IgG with high affinity and is expressed after IFN- $\gamma$ activation [18]; Fc $\gamma$ RII (CD32), which has a pivotal role in IgG-induced activation and neutrophil phagocytosis [19]; and FcyRIII (CD16), which is present in neutrophils involved in immune complexes binding and is thus important for cell adhesion [20].

CR1 and CD32 localized in neutrophils promote IC adherence, thereby increasing phagocytosis [21]. CR1/CD32 interaction with IC increases oxidative burst and neutrophil degranulation compared to IC interaction with each receptor alone, giving evidence of a synergistic cooperation [22]. Inherited or acquired defects concerning the interaction between CR1 and CD32 may contribute to tissue injury [23].

The complement system has a pivotal role in the pathogenesis of various human IC-mediated disorders, including systemic lupus erythematosus, vasculitis, glomerulonephritis, and RA [24]. However, the role played by the complement system in RA is less well understood. Certain complement system components are deposited in RA patients' synovial tissues. These components levels in RA patients' SF are often depressed, which reflects their consumption, while complement components cleavage fragments levels are commonly elevated [25]. Total hemolytic complement, C3, and C4 levels are reduced in RA patients' SF as compared to total protein level [26].

Considering the major role played by neutrophils in RA pathogenesis as well as the scarcity of data regarding complement system participation at the systemic level, we have designed a study in order to simultaneously evaluate the function (respiratory burst and chemotaxis) and membrane

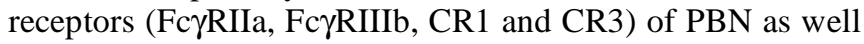
as the complement system serum activity (classic and alternative pathway) in RA patients stratified according to disease activity.

\section{PATIENTS AND METHODS}

\section{Subjects}

Twenty-seven female RA patients (11 with active disease and 16 with inactive disease), aged 25 to 50 years (median $=$ 45 years), followed at the University Hospital of Faculdade de Medicina de Ribeirão Preto, University of São Paulo, Brazil, were included in the present study. All the patients fulfilled the classification criteria of the American College of Rheumatology [27]. As for disease activity, active RA patients had a median Disease Activity Score (DAS) 28 of 5.01, whereas inactive patients presented a median DAS 28 of 2.1. All the patients were taking methotrexate (10-15 $\mathrm{mg} /$ week) and prednisone (5-10 mg/day). Blood was collected from active RA patients before any introduction of additional drugs. Twenty-seven age-matched healthy women presenting no personal or family history of RA were also studied. The local Research Ethics Committee approved the study protocol (10097/2002), and a written informed consent for participation in the study was signed by all the participants.

\section{Neutrophil Isolation}

Human peripheral blood was collected from the healthy volunteers and RA patients using Alsever solution ( $\mathrm{pH} \mathrm{6.1).}$
Polymorphonuclear (PMN) neutrophils were isolated in a gelatin gradient as previously described [28]. This procedure allowed for recovery of up to $95 \%$ of PMN cells. All reagents and glassware were lipopolysaccharide-free when tested with E-TOXATE1 (Sigma, Saint Louis, MO, USA).

\section{ROS Production (oxidative Burst) by Neutrophils}

\section{Immune Complex (IC)}

Anti-ovalbumin (OVA) IgG was prepared from the serum of rabbits that had been hyperimmunized with ovalbumin (OVA; Sigma, product no. A - 5503) as previously described [29, 30].

The total IgG fraction was purified by ion exchange chromatography on a diethylaminoethyl (DEAE) column. Fractions were tested for IgG purity by sodium dodecyl sulfate polyacrylamide gel electrophoresis (SDS-PAGE) [31] and immunoelectrophoresis.

ICs formed at equivalence were prepared from mixtures of rabbit anti-OVA IgG and OVA by incubation at $37^{\circ} \mathrm{C}$ for $1 \mathrm{~h}$, followed by incubation at $4^{\circ} \mathrm{C}$ overnight. After centrifugation at $12,000 \mathrm{xg}$, the precipitates were washed and resuspended in $0.15 \mathrm{M} \mathrm{NaCl}$. These ICs were used in the assay systems as suspensions, having been gently homogenized by inversion immediately before use. It is noteworthy that an IC formed by an antibody produced in rabbits is efficient stimulus for human neutrophils activation, as reported in the literature [22, 32-34].

\section{ICs Opsonization}

Pooled normal human serum (NHS), control normal serum (CHS), and RA serum (RAHS) were obtained from blood samples collected in the absence of anticoagulant and were used as the complement source. ICs were incubated at $37^{\circ} \mathrm{C}$ with NHS (IC-NHS) or RAHS (IC-RAHS) diluted 1:2 in veronal-buffered saline containing $0.25 \mathrm{mM} \mathrm{CaCl}_{2}$ and $0.83 \mathrm{mM} \mathrm{MgCl}$, $\mathrm{pH}$ 7.2. After incubation for $30 \mathrm{~min}$, cold PBS (phosphate buffered saline), $\mathrm{pH} 7.4$, was added to the mixtures, which were then centrifuged at $4{ }^{\circ} \mathrm{C}$ for $10 \mathrm{~min}$. The pellets containing IC were washed once with $\mathrm{PBS}, \mathrm{pH}$ 7.4, and resuspended in Hanks' balanced salt solution (HBSS), $\mathrm{pH}$ 7.2. Therefore, at the end of this preparation the following ICs were achieved: IC (IgG-IC: IC alone or in the absence of serum for opsonization), NHS-IC (IC opsonized with pooled normal human serum), and RAHS-IC (IC opsonized with RA human serum), which were employed in the chemoluminescence (CL) assays for neutrophils stimulation.

Oxidative burst was evaluated using two different methods. In one of them, neutrophils were incubated with IC alone, to assess the cell response mediated by Fc $\gamma$ receptors. For the second method, neutrophils were incubated with NHS-IC or RAHS-IC, to evaluate the cell response mediated by Fc $\gamma$ and complement receptors, and the cooperation between these two receptors was estimated. The CL assay for ROS detection was performed as previously described [35]. Briefly, neutrophils diluted at $1 \times 10^{6}$ cells/ mL in HBSS $/ 0.1 \%$ gelatin, $\mathrm{pH} 7.2$, were mixed with $80 \mu \mathrm{g}$ of the different ICs (IC, NHS-IC, or RAHS-IC) in the presence of $10^{-4} \mathrm{M}$ luminol (Sigma). The reaction was monitored with a luminometer (Autolumat LB953, EG\&G Berthold, Hannover, Germany) at $37^{\circ} \mathrm{C}$, for $10 \mathrm{~min}$ and recorded in millivolts $(\mathrm{mV})$. Neutro- 
phils incubated with luminol and HBSS in the absence of IC were utilized as controls. The results are expressed as the area under the curve of the CL profile and recorded as $\mathrm{cpm} /$ minute as a function of time.

\section{Neutrophil FcyR and CR Expression}

Fc $\gamma \mathrm{R}$ and $\mathrm{CR}$ expression was detected by flow cytometry using the following antibodies: (a) fluorescein isothiocyanate (FITC)-conjugated mouse monoclonal-anti-human Fc $\gamma$ RII/ CD32 (555448; clone FLI 8.26; IgG2b,k), non-specific isotype control (555742; clone 27-35; IgG2b,k), antiCR1/CD35 (555452; clone E11; IgG1,k); and (b) phycoerythrin (PE)-conjugated mouse monoclonal-anti-human FcyRIII/CD16 (555407; clone 3G8; IgG1,k), non-specific isotype control (555749; clone MOCPC-21; IgG1,k), and anti-human CR3/CD11b/Mac-1 (555388; clone ICRF 44; IgG1,k). All antibodies were acquired from BD PharMingen (San Diego, CA, USA). An FITC-mouse IgG1, k/PE-mouse IgG1,k (Simultest control 349526, Becton Dickinson; San Jose, CA, USA) was also used as a non-specific control. Venous blood $(100 \mathrm{~mL})$ treated with EDTA was incubated at room temperature, in the dark, for $20 \mathrm{~min}$, using saturating concentrations of labeled antibodies for Fc $\gamma$ RII, Fc $\gamma$ RIII, $\mathrm{CR} 1$, and CR3 and control antibodies for $\mathrm{IgG} 1, \mathrm{k}$ and IgG2b,k. Erythrocytes were hemolyzed by addition of $2 \mathrm{~mL}$ Facslysing solution (Becton Dickinson). After $10 \mathrm{~min}$ at room temperature, cells were centrifuged and washed once with $2 \mathrm{~mL}$ cold $\mathrm{PBS} / 2 \%$ fetal calf serum $(\mathrm{FCS}) / \leq 0.1 \%$ sodium azide, $\mathrm{pH}$ 7.4. The cells were resuspended in $500 \mu \mathrm{L}$ $\mathrm{PBS} / 1 \%$ formaldehyde, $\mathrm{pH} 7.4$, for flow cytometry, using an FACSort, fluorescence-activated cell sorter; (Becton Dickinson). A 488-nm excitation source and standard fluorescein filters were employed for FITC- and PE-fluorescence measurements. Neutrophils were identified using a forward and right-angle light scatter. The relative number of positive neutrophils and the median channel fluorescence intensity (MCFI) for each antibody were measured as an indication of receptor density. The fluorescence histograms were obtained on a logarithmic scale. Isotype control antibodies were used to set background levels.

\section{Hemolytic Complement Activity}

\section{Alternative Pathway}

The method of Polhill et al. (1978) [36] was employed. Briefly, fresh rabbit blood was filtered through cotton, mixed with the same volume of TEA/EDTA buffer (TEA: Triethanolamine $-0.02 \mathrm{M}$ buffer containing $0.005 \mathrm{M}$ azide, $\mathrm{pH}$ 7.2), (TEA/EDTA: TEA containing $0.01 \mathrm{M}$ ethylenediamine tetraacetic acid), and incubated for $15 \mathrm{~min}$ at $37^{\circ} \mathrm{C}$. The suspension was then centrifuged, red cells were washed three times in TEA/Mg ${ }^{++}$buffer (TEA containing 0,002 $\mathrm{M}$ magnesium), resuspended in Alsever's modified solution, and stored at $4^{\circ} \mathrm{C}$. Prior to use in hemolytic assays, cells were washed three times in TEA/EGTA/ $\mathrm{Mg}^{++}$buffer and then resuspended at a standard concentration (monitored at 700 $\mathrm{nm}$ as described above). The lytic activity was determined by mixing a rabbit cell suspension and serum diluted in TEA/EGTA/ $\mathrm{Mg}^{++}$.

\section{Determination of Fragment $\mathrm{Bb}$ and C5a by ELISA}

Fragment $\mathrm{Bb}$ and $\mathrm{C} 5 \mathrm{a}$ were quantified by an enzymelinked immunosorbent assay, as described in detail in Mi-
croVue Complement BbPlus and Complement C5a EIA Kit QUIDEL $^{\circledR}$, respectively.

\section{Neutrophil Chemotaxis Assay}

Patients' and control sera chemotactic activity were evaluated in vitro by modification of the technique described by Boyden [37], using acrylic migration chambers.

Zymosan (Zy), a polysaccharide responsible for cell activation, was employed for chemotactic fragments generation. To this end, $50 \mathrm{mg} \mathrm{Zy}$ were heated in a water bath for 30 minutes. Next, Zy was transferred to a Falcon tube and centrifuged at 2,000rpm for 5 minutes. The supernatant was discarded, and 5mL CFD (complement fixation diluents)/gel buffer $(10 \mathrm{mg} / \mathrm{mL})$ were added to the tube, which was then stored in a refrigerator.

On the day of the experiment, $75 \mu \mathrm{L} \mathrm{Zy} \mathrm{were} \mathrm{transferred}$ to a test tube (positive tube). This tube was centrifuged, and the supernatant was discarded. Then, $120 \mu \mathrm{L}$ serum (RA patient or control) and $100 \mu \mathrm{L}$ CFD/gel were added. In another test tube (negative tube), only $120 \mu \mathrm{L}$ serum and $100 \mu \mathrm{L}$ $\mathrm{CFD} / \mathrm{gel}$ were added. Both tubes were incubated at $37^{\circ} \mathrm{C}$ for 40 minutes, followed by centrifugation at 2,000rpm for 5 minutes, and the supernatant was transferred to other test tubes. These test tubes were then incubated at $56^{\circ} \mathrm{C}$ for 30 minutes, for residual CS (complement system) inactivation. After this period, the sera were diluted in Hanks/gel (1:5 dilution) and applied to Boyden chambers for chemotactic activity evaluation.

In the chemotactic assay, the lower chamber compartment was filled with $0.2 \mathrm{~mL}$ diluted and appropriately inactivated serum collected from RA patients or control. The compartment was then covered with filters with diameter and pores size of $13 \mathrm{~mm}$ and $3 \mu \mathrm{m}$, respectively (SSWP 01300, Millipore Corp., Bedford,USA). The upper well was filled with $0.3 \mathrm{~mL}$ neutrophils suspension containing $2.0 \times 10^{6}$ cells $/ \mathrm{mL}$, and the chambers were then incubated at $37^{\circ} \mathrm{C}$ for 30 minutes, in humidified atmosphere. After the incubation period the filters were removed, fixed in 2-propanol, stained with Harris hematoxylin, dehydrated in 2-propanol, bleached with xylene, and mounted between slides and coverslips with the aid of Entellan (Merck). Neutrophils migration was determined by means of the leading front technique [38], by measuring the largest distance, in micrometers, crossed by three cells per field using a 100x objective. At least 10 fields were examined per filter. The obtained data were plotted in a graph using the software Graphpad Prism version 3.00 for Windows.

\section{Statistical Analysis}

The non-parametric Mann-Whitney (for two groups), Wilcoxon (matched pairs), and Kruskal-Wallis (for three groups) tests were employed. Dunn's multiple comparisons test was used when differences were detected by the Kruskal-Wallis test. Correlations were determined using the Spearman rank correlation coefficient. P values $<0.05$ were considered significant. Dunnett's multiple comparison test and Tukey's multiple comparison test were utilized.

\section{RESULTS \\ ROS Production}

ROS production stimulated by different ICs (IC alone, NHS-IC, and RAHS-IC) in RA patients and controls is 
shown in Figs. (1A-C). Comparison of the oxidative burst mediated by Fc $\gamma \mathrm{R}$ (IC alone) in patients and controls did not reveal significant differences. Compared to the oxidative burst mediated by $\mathrm{Fc} \gamma \mathrm{R}$ alone, ROS production mediated by Fc $\gamma \mathrm{R}$ and CR resulted in increased responses in patients with active or inactive RA as well as in controls ( $p<0.05$ for each comparison) when neutrophils were incubated with NHS-IC. When the cells were stimulated with ICs opsonized with their own serum or autologous serum, only neutrophils from healthy volunteers (control) had significantly enhanced ROS production (Fig. 1C- CHS-IC).
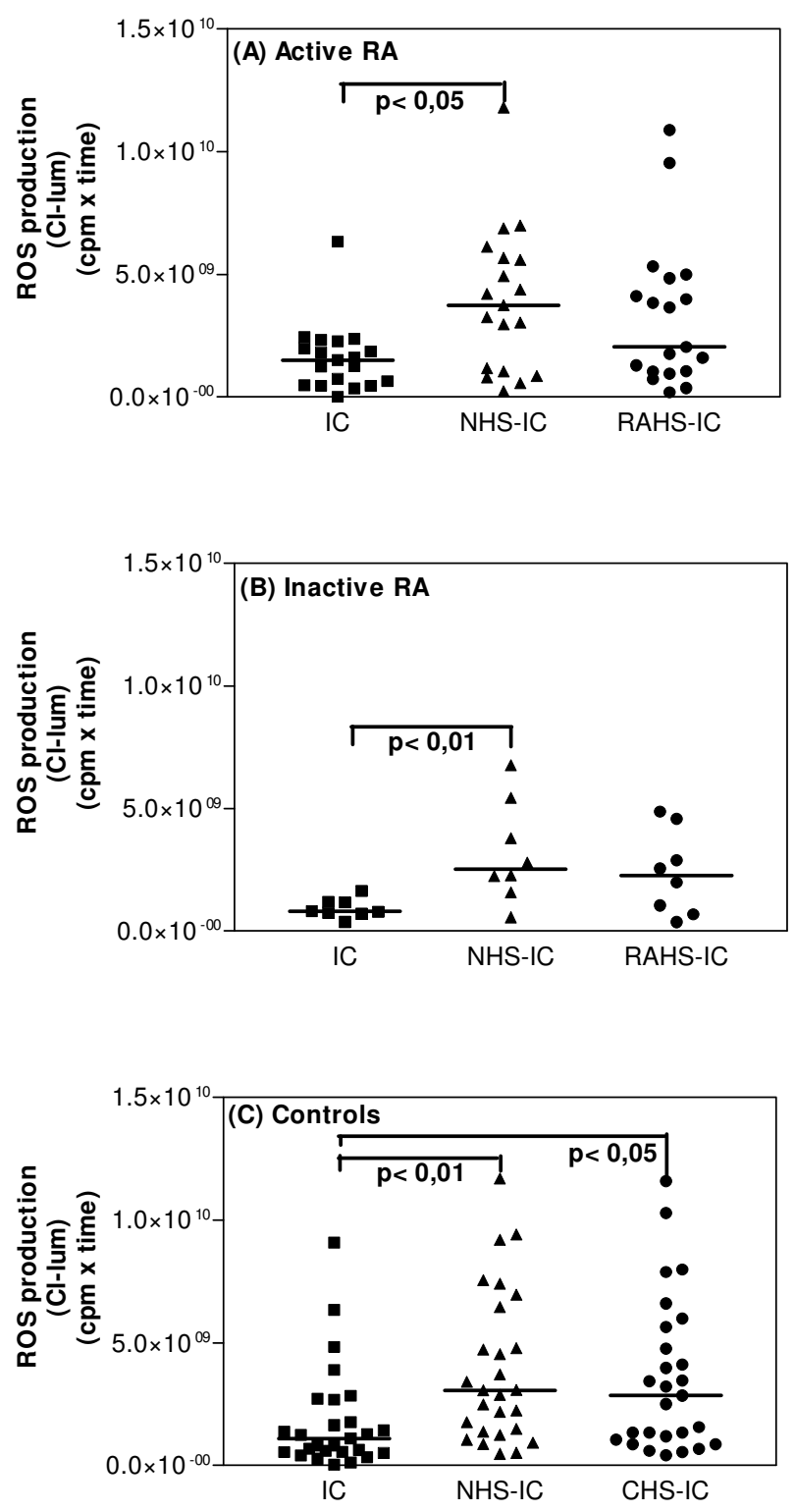

Fig. (1). ROS production by neutrophils stimulated with immune complex-IC: IgG-IC (IC alone in the absence of serum for opsonization), NHS-IC (IC opsonized with pooled normal human serum), RAHS-IC (IC opsonized with rheumatoid arthritis human serum), and CHS-IC (IC opsonized with healthy control human serum). Panel A - active RA patients, B - inactive RA patients, and $\mathbf{C}$ healthy controls. ROS production was measured by chemiluminescence $(\mathrm{CL})$ assay, and the results are presented as medians of area under CL profiles in cpm.

\section{Neutrophil Fc $\gamma R$ and CR Expression}

Fc $\gamma R$ s (Fc $\gamma R$ IIa/CD32 and Fc $\gamma R$ IIIIb/CD16), CR1 (CD35), and CR3 (CD11b/CD18) expression in the RA patients' and control neutrophils is presented in Figs. (2A-D).

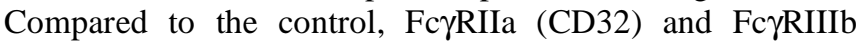
(CD16) expression in active and inactive RA patients' neutrophils was not statistically different (Figs. 2A and 2B). However, CD32 expression in active RA patients was higher compared to healthy controls and inactive RA patients. As for CR1 expression, it was increased in active RA patients' neutrophils compared to controls (Fig. 2C - $P<0.05$ ), whereas no difference was observed in the case of inactive RA patients. CR3 expression was significantly increased in active RA patients compared to inactive RA patients (Fig. 2D - $P<0.05)$. Comparison between RA patients and controls did not reveal any significant difference.

\section{Correlations between Fc $\gamma$ Rs and CRs}

Several correlations were determined regarding Fc $\gamma \mathrm{Rs}$ and CRs expression on polymorphonuclear cells surface. Overall, FcyRs expression correlated positively with CRs expression in RA patients and controls (Figs. 3A-D).

\section{Hemolytic Complement Activity}

The alternative complement pathway activity in active RA patients was significantly increased in relation to controls $(p=0.0183)$ (Fig. 4). This effect was not observed in inactive RA patients of alternative pathway (data not show) and on the classical complement pathway activity (data not show).

\section{Fragment Bb Concentration}

Fig. (5) depicts the $\mathrm{Bb}$ fragments concentration in RA patients' and healthy controls' sera. Bb concentration indicates occurrence of the alternative complement pathway. There was a statistically significant rise $(\mathrm{p}<0.01)$ in $\mathrm{Bb}$ concentration in active RA patients' serum compared to healthy controls.

\section{Neutrophils Chemotaxis}

Neutrophils obtained from healthy individuals exhibited increased migration after serum activation with zymosan $(\mathrm{p}<$ $0.05)$. After serum inactivation by heat, neutrophil migration returned to basal levels. On the other hand, when healthy individuals' neutrophils were incubated with active RA patients' serum (activated or not by zymosan), migration levels increased in a closely similar way ( $p>0.05$ for each comparison). After serum inactivation by heat, neutrophil migration decreased, but it did not return to basal values. Fig. (6) shows some of these results.

\section{C5a Concentration}

In order to investigate the complement system systemic activation, C5a concentration in RA patients' and healthy controls' serum was evaluated (Fig. 7). There was a significant rise in serum C5a levels in the case of RA patients, which were statistically higher than those measured in healthy subjects $(\mathrm{p}<0.05)$.

\section{DISCUSSION}

The role played by the complement system in RA remains controversial. Many studies have reported increased 

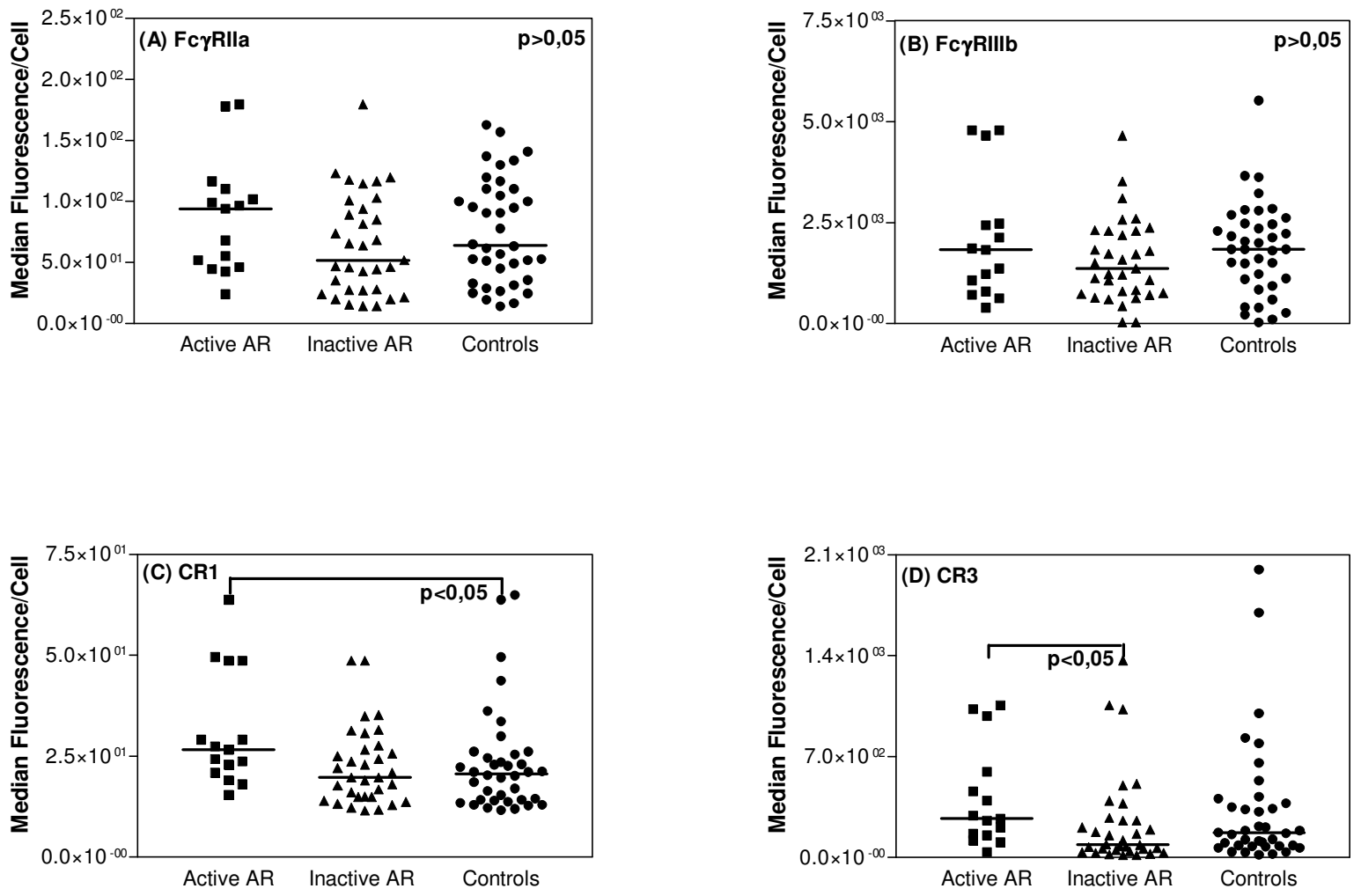

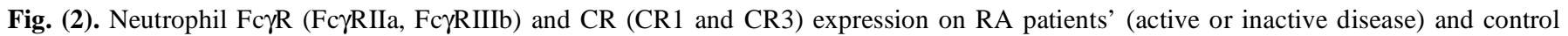
neutrophils surface, as determined by flow cytometry. Cells from RA patients stained with fluorescein isothiocyanate (FITC)-conjugated mouse monoclonal-anti-human Fc $\gamma$ RIIa/CD32 and monoclonal-anti-human CR1, phycoerythrin (PE)-conjugated mouse monoclonal-antihuman Fc $\gamma$ RIIIb/CD16 and monoclonal-anti-human CR3. Panel A - Fc $\gamma$ RIIa, B - Fc $\gamma$ RIIIb, C - CR1, D - CR3.
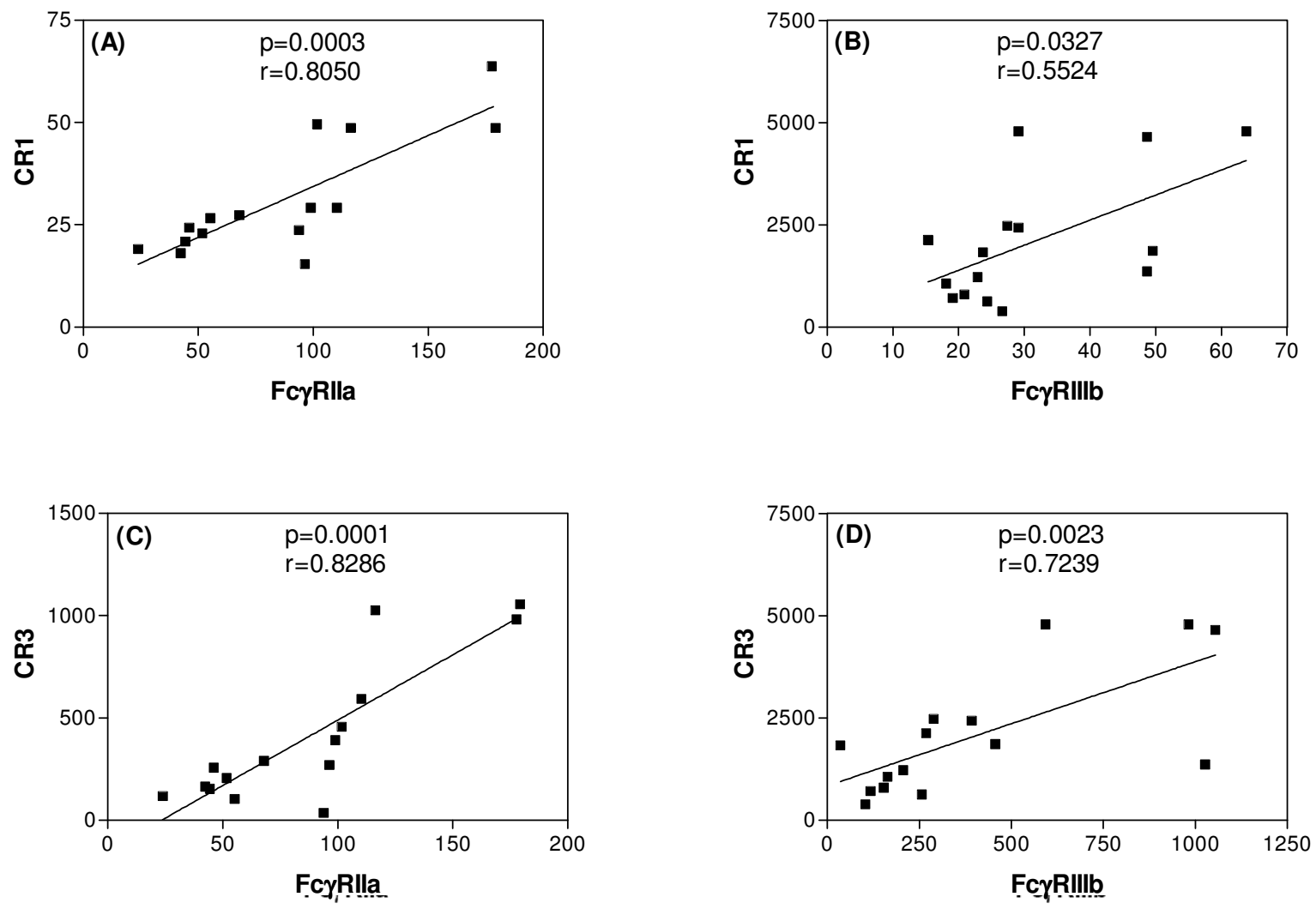

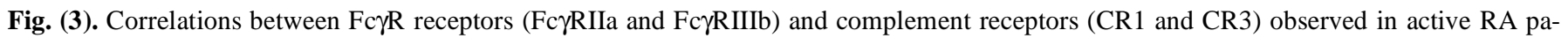
tients. Panel A - CR1 versus Fc $\gamma$ RIIa, B - CR1 versus Fc $\gamma$ RIIIb, C - CR3 versus Fc $\gamma$ RIIa, D - CR3 versus Fc $\gamma$ RIIIb. 


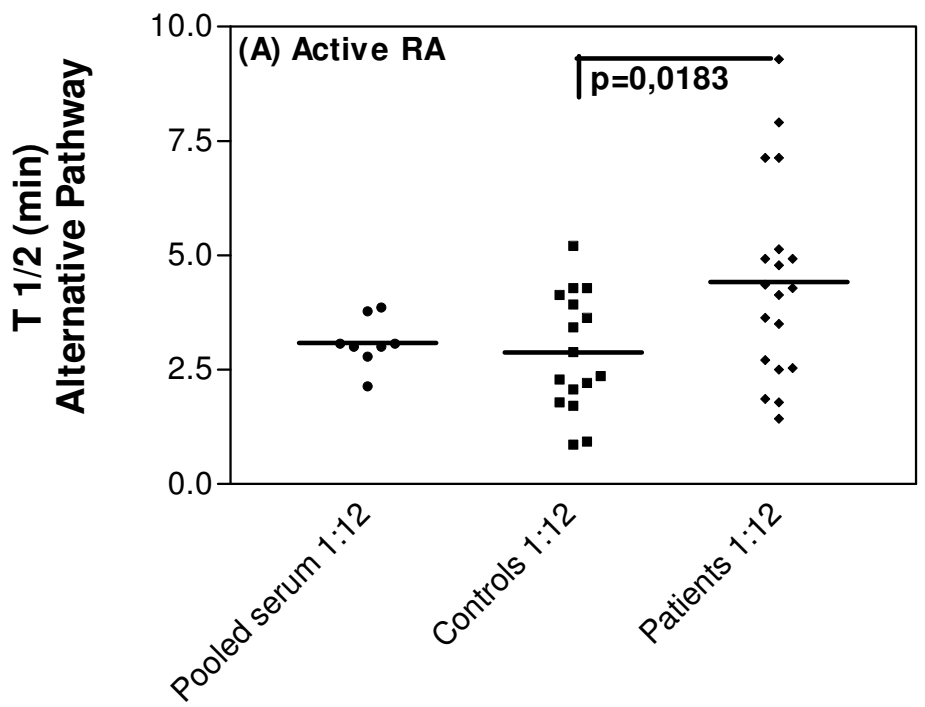

Fig. (4). Complement alternative pathway serum hemolytic activity in active RA patients. $T^{1} / 2$ time (min) required for the serum complement to cause $50 \%$ antibody-sensitized rabbit erythrocytes lysis. The $\mathrm{T}^{1} / 2$ values are inversely proportional to the hemolytic activity. Bars represent the medians.

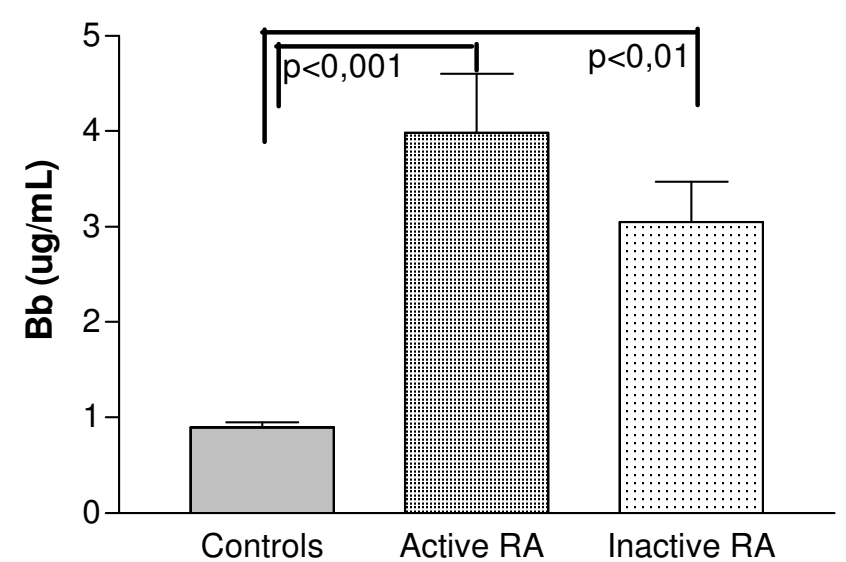

Fig. (5). Bb concentration in active and inactive RA patients' and control serum, as determined by ELISA.

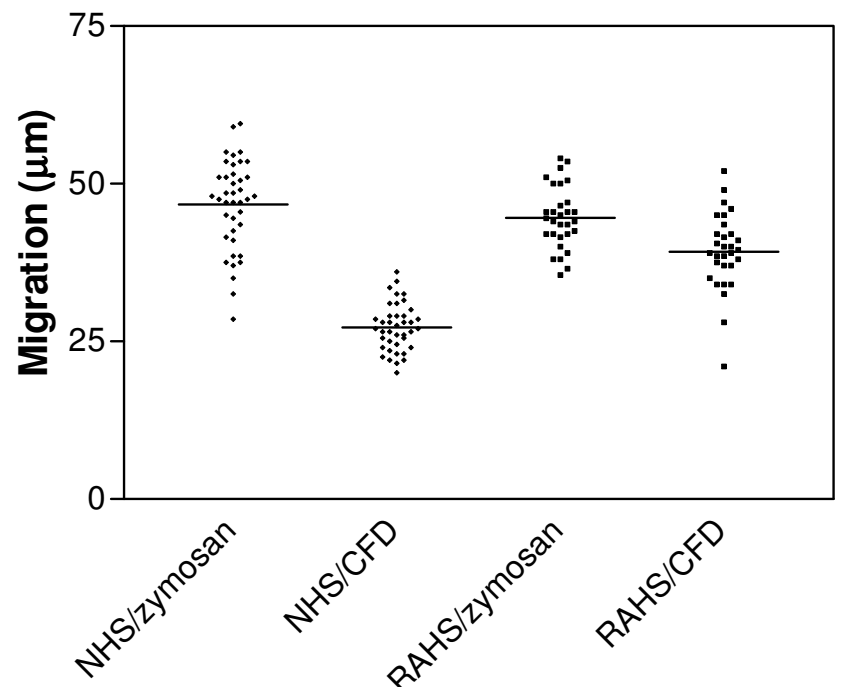

Fig. (6). Chemotaxis of neutrophils incubated with zymosan (positive control), complement fixation diluent (CFD-negative control), normal human serum (NHS), or RA human serum (RAHS) obtained from active RA patients. Bars represent median values.

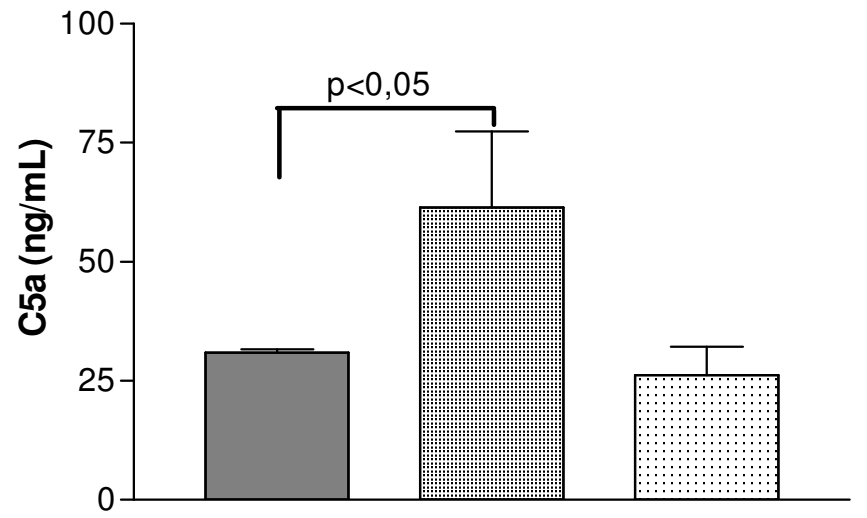

Fig. (7). C5a concentration in active and inactive RA patients' and control serum, as determined by ELISA.

activity for this complement system in the SF, particularly with respect to the alternative pathway [39-42]; however, very few studies on complement system alterations at the systemic level have been reported. In the present investigation, we have simultaneously evaluated PBN function (respiratory burst and chemotaxis) and membrane receptors

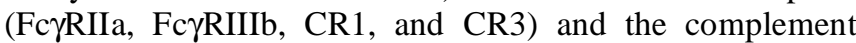
systemic activity (classic and alternative pathway) in RA patients stratified according to disease activity.

The difference between RA patients and controls concerning neutrophil respiratory burst as evaluated by ROS production after IC phagocytosis was not statistically significant (Figs. 1A, B, C - neutrophils stimulated with IgG-IC). However, results analysis showed increased IgG-ICstimulated neutrophils oxidative metabolism in the case of active RA patients (Fig. 1A). Bearing in mind that this effect was not detected for inactive RA patients or healthy controls (Figs. 1B and 1C), it can be suggested that these cells are activated in active RA patients (neutrophils stimulated with IgG-IC: median for active RA patients $=1.51 \mathrm{X} 10^{9}$; median for inactive RA patients $=0.8 \times 10^{9}$, median for controls $=$ $\left.1.1 \times 10^{9}\right)$. 
In addition, incubation of RA patients' or control neutrophils with NHS-IC significantly increased ROS production. These results indicate that the NHS complement was activated, providing more complement activation ligands and better cooperation between complement and $\mathrm{Fc}$ receptors, thereby facilitating IC phagocytosis and increasing ROS production (Figs. 1A-C - IC versus NHS-IC). When neutrophils were stimulated with autologous sera, healthy neutrophils increased the oxidative burst, whereas RA neutrophils obtained from active or inactive RA patients did not undergo any changes. Taken together, these findings give an indication that RA neutrophils active and inactive RA patients respond to the complement exogenous source (NHS-IC); however, there is poor FcR/CR cooperation, as evidenced by RA neutrophils incubation with autologous sera. Moreover, these results hint that FcRs and CRs expression alteration; complement regulatory system alteration, or complement systemic activation occurs.

The complement system is increasingly recognized as being causally involved in tissue injury in ischemic, inflammatory, and autoimmune diseases [43, 44]. Immune complexes activate the complement, become opsonized by early complement components, and are finally taken up by phagocytes carrying CRs and FcRs [45]. Increased SF neutrophil complement (CR1, CR2, and CR3) and FcyR [13, 46-48] have been reported in RA patients; however, information regarding CRs and FcRs expression in PBN is scarce. In the present study it was possible to observe that CR1 and CR3 neutrophil expression was increased in active RA patients (Figs. 2C and 2D). Furthermore, although the Fc $\gamma$ RIIa and Fc $\gamma$ RIIIb expression observed in RA patients was not significantly different from that measured in controls (Fig. $\mathbf{2 A}$ and 2B), significant positive correlations between CRs and Fc $\gamma \mathrm{R}$ were only observed for active RA patients (Figs. 3A-D), indicating that $\mathrm{PBN}$ are also activated in these patients.

Apart from cooperating with FcR, CRs may also function as complement regulatory proteins, particularly $\mathrm{CR} 1$, which is an important regulator of the classical and alternative complement pathways $[49,50]$. CR1 exerts a decayaccelerating activity for $\mathrm{C} 3 / \mathrm{C} 5$ convertase [51], being a cofactor for the serine protease factor I, which in turn mediates $\mathrm{C} 3 \mathrm{~b}$ and $\mathrm{C} 4 \mathrm{~b}$ degradation. Although the complement system regulatory components were not evaluated here, some of our results indicate that $\mathrm{CR} 1$ may have a regulatory role in $\mathrm{RA}$ patients. Considering that ROS production by RA neutrophils mediated by FcR and CR (RAHS-IC) did not increase as much as that mediated by FcR (IC) only (Fig. 1A), and taking into account the fact that CR1 was significantly elevated in RA neutrophils, particularly in the case of the active disease, one may hypothesize that higher CR1 levels in PBN may regulate the cell response before reaching the synovia.

Despite the several studies describing complement system activation at the synovial level, particularly of the alternative pathway, few studies have evaluated the activity of both the classical and alternative pathways in RA patients stratified according to disease activity. We evaluated the classical pathway hemolytic activity and observed in the RA patients included in this study did not differ from that of the controls (data not show). However, activation of the alternative pathway was detected in active RA patients' serum (Fig.
4). No differences were detected between patients with inactive disease and controls (data not show).

In order to assess the contribution of the alternative pathway, Bb concentration, a product of alternative pathway activation, was measured in serum samples taken from RA patients and controls. There was significant increase in $\mathrm{Bb}$ levels in the case of active RA patients' serum compared to healthy controls (Fig. 5), corroborating the complement activation previously detected in the hemolytic assay. In inactive $\mathrm{RA}$ patients, detection of low Bb concentrations as compared to healthy controls suggests the action of drugs such as immunosuppressors, immunomodulators, and anti-inflammatory agents which were employed for RA treatment in these patients [42-44].

Banda et al. [41] have demonstrated that factor B and the alternative complement pathway play an essential role in the development of joint inflammation and damage in the anti$\mathrm{CII}$ mAb-passive transfer arthritis model. Inflammatory joint disease in $\mathrm{K} / \mathrm{BxN}$ mice improves in factor $\mathrm{B}-/$ - but not in $C 4$ -/- animals [40]. In addition, a high-molecular-weight IgA rheumatoid factor-containing IC, which can activate the alternative pathway, has been reported in children with polyarticular disease [52] as well as in adults with RA [53, 54]. Finally, it is important to emphasize that the alternative pathway always acts as an efficient amplification loop through the classical or lectin pathways [39].

To further investigate the influence of the complement system systemic alterations in RA patients, the chemotaxic activity of normal neutrophils incubated with RAHS or NHS was examined. The incubation of zymosan with NHS or RAHS generated sufficient complement-derived chemoattractant factors to increase neutrophil migration in the Boyden chamber membrane. When cells were incubated with NHS only; i.e., without the complement activator (zymosan), normal neutrophils did not display increased migration, whereas enhanced migration was observed when cells were incubated with RAHS without zymosan, (Fig. 6). These results indicate that RAHS contains chemoattractant factors even before zymosan activation occurs, corroborating the idea of systemic complement system activation in active RA patients. In order to confirm this finding, C5a concentration in patients' and control serum samples was analyzed. The C5a concentration in active RA patients was higher, as compared to healthy individuals, contrary to what was observed in the case of inactive RA patients (Fig. 7). These results confirm that complement system activation takes place in active RA patients' systemic circulation. Furthermore, C5a is a potent promoter of inflammation, having strong chemotaxic properties, in particular for neutrophils.

In summary, the present work has demonstrated systemic complement system alternative pathway activation in active RA patients, which has implications for the peripheral neutrophils effector functions.

\section{CONCLUSIONS}

In conclusion, the results of the present study indicated that several abnormalities of the complement system exist at the systemic level, namely impaired membrane receptor cooperation, alternative pathway activation, and presence of pre-existing chemoattractant factors in the serum. Together, 
these abnormalities may synergistically contribute to RA pathogenesis.

\section{ACKNOWLEDGEMENTS}

We thank Patrícia V. B. Palma, Fabiana Rossetto de Morais, and A.C.M. Polizelo for technical assistance; Dr Flávio Calil Petean and Dr Fabíola Reis for help in selecting RA patients; Dr Marcelo Dias Baruffi and Dr Luciana Kabeya for scientific discussions; and Dr Ana Paula Landi Librandi for assistance with ELISA assays. This study was supported by CAPES, CNPq (Grant 473657/2007-4), and FAPESP (Grant 02/06800-4) Brazil.

\section{REFERENCES}

[1] Cascão R, Rosário HS, Souto-Carneiro MM, Fonseca JE. Neutrophils in rheumatoid arthritis: more than simple final effectors. Autoimmun Rev 2010; 9(8):531-5.

[2] Cascão R, Rosário HS, Fonseca JE. Neutrophils: warriors and commanders in immune mediated inflammatory diseases. Acta Reumatol Port 2009; 34(2B): 313-26.

[3] Johnson KJ, Varani J, Smolen JE. Neutrophil activation and function in health and disease. Immunol Ser 1992; 57: 1-46.

[4] Weiss SJ. Tissue destruction by neutrophils. N Engl J Med 1989; 320: 365-76.

[5] Curnutte JT, Babior BM. Advances in human genetics. New York: Plenum Publishing 1987.

[6] Dai L, Lamb DJ, Leake DS, et al. Evidence for oxidised low density lipoprotein in synovial fluid from rheumatoid arthritis patients. Free Radic Res 2000; 32(Suppl 6): 479-86.

[7] Hitchon CA, El-Gabalawy HS. Oxidation in rheumatoid arthritis. Arthritis Res Ther 2004; 6(Suppl 6): 265-78.

[8] Hacbarth E. Kajdacsy-Balla A. Low density neutrophils in patients with systemic lupus erythematosis, rheumatoid arthritis, and acute rheumatic fever. Arthritis Rheum 1986; 29: 1334.

[9] McCarthy DA, Holburn CM, Pell BK, et al. Scanning electron microscopy of rheumatoid arthritis peripheral blood polymorphonuclear leukocytes. Ann Rheum Dis 1986; 45: 899.

[10] Kumar V, Sharma A. Neutrophils: cinderella of innate immune system. Int Immunopharmacol 2010; 10: 1325-34.

[11] Wright HL, Moots RJ, Bucknall RC, Edwards SW. Neutrophil function in inflammation and inflammatory diseases. Rheumatology (Oxford). 2010; 49(9) :1618-31.

[12] Blouin E, Halbwachs-Mecarelli L, Rieu P. Redox regulation of beta2-integrin CD11b/CD18 activation. Eur J Immunol 1999; 29(Suppl 11): 3419-31.

[13] Crockard AD, Thompson JM, Mcbride SJ, et al. Markers of Inflammatory activation: upregulation of complement receptors CR1 and CR3 on synovial fluid neutrophils from patients with inflammatory joint disease. Clin Immunol Immunopathol 1992; 65: 13542.

[14] Wong WW, Jack RM, Smith JA, et al. Rapid purification of the human $\mathrm{C} 3 \mathrm{~b} / \mathrm{C} 4 \mathrm{~b}$ receptor (CR1) by monoclonal antibody affinity chromatography. J Immunol Methods 1985; 82(Suppl 2): 303-13

[15] Gordon DL, Johnson GM, Hostetter MK. Characteristics of iC3b binding to human polymorphonuclear leucocytes. Immunology 1987; 60(Suppl 4): 553-8.

[16] Beller DI, Springer TA, Schreiber RD. Anti-Mac-1 selectively inhibits the mouse and human type three complement receptor. J Exp Med 1982; 156(Suppl 4): 1000-9.

[17] Mosser DM, Edelson PJ. The mouse macrophage receptor for C3bi (CR3) is a major mechanism in the phagocytosis of Leishmania promastigotes. J Immunol 1985; 135(Suppl 4): 2785-9.

[18] Kleinau S, Martinsson P, Heyman B. Induction and suppression of collagen-induced arthritis is dependent on distinct $\mathrm{Fc} \gamma$ receptors. J Exp Med 2000; 191: 1611-6.

[19] Graziano RF, Fanger MW. Fc gamma RI and Fc gamma RII on monocytes and granulocytes are cytotoxic trigger molecules for tumor cells. J Immunol 1987; 139(Suppl 10): 3536-41.

[20] Gresham HD, Clement LT, Lehmeyer JE, et al. Stimulation of human neutrophil Fc receptor-mediated phagocytosis by a low molecular weight cytokine. J Immunol 1986; 137(3): 868-75.
[21] Neumann E, Barnum SR, Tarner IH, et al. Local production of complement proteins in rheumatoid arthritis synovial. Arthritis Rheum 2002; 46: 934-45.

[22] Lucisano YM, Mantovani B. The role of complement in the stimulation of lysosomal enzyme release by polymorphonuclear leukocytes induced by immune complexes of IgG and IgM. Immunology 1988; 65: 171-5.

[23] Colten HR, Rosen FS. Complement deficiences. Annu Rev Immunol 1992; 10: 809-34.

[24] Tsokos GC, Fleming SD. Autoimmunity, complement, activation, tissue injury and reciprocal effects. Curr Dir Autoimmun 2004; 7: 149-64.

[25] Utsinger PD, Zvaifler NJ, Ehrlich GE. Rheumatoid arthritis: etiology, diagnosis, management. Philadelphia: JB Lippincott 1985.

[26] Morgan BP. Measurement of complement hemolytic activity, generation of complement-depleted sera, and production of hemolytic intermediates. Methods Mol Biol 2000; 150: 61-71.

[27] Arnett FC, Edworthy SM, Bloch DA, et al. The American Rheumatism Association 1987 revised criteria for the classification of rheumatoid arthritis. Arthritis Rheum 1988; 31: 315-24.

[28] Lucisano-Valim YM, Mantovani B. Lysosomal enzyme release from polymorphonuclear leukocytes induced by immune complexes of IgM and IgG. J Immunol 1984; 132: 2015-20.

[29] Lucisano-Valim YM, Kabeya LM, Kanashiro A, et al. A simple method to study the activity of natural compounds on the chemiluminescence of neutrophils upon stimulation by immune complexes. J Pharmacol Toxicol Methods 2002; 47: 53-8.

[30] Dresser DW. Immunization of experimental animal. In: Weir DM Ed Handbook of experimental immunology. Oxford: Black-well 1986; 8.1-8.21

[31] Laemmli UK. Cleavage of structural proteins during the assembly of the head of bacteriophage T4. Nature 1970; 227(5259): 680-5.

[32] Crockett-Torabi E, Smith CW, Kateley JR, et al. Insoluble immune complex-stimulated neutrophil leukotriene B4 production is dependent on Fc gamma RII and Fc gamma RIII and independent of pertussis toxin-sensitive signal transduction pathways. Am J Pathol 1992; 140(3): 613-20.

[33] Fossati G, Bucknall RC, Edwards SW. Insoluble and soluble immune complexes activate neutrophils by distinct activation mechanisms: changes in functional responses induced by priming with cytokines. Ann Rheum Dis 2002; 61(1): 13-9.

[34] Fairhurst AM, Wallace PK, Jawad AS, et al. Rheumatoid peripheral blood phagocytes are primed for activation but have impaired Fc-mediated generation of reactive oxygen species. Arthritis Res Ther 2007; 9(2): R29.

[35] Marzocchi-Machado CM, Alves CMOS, Azzolini AECS, et al. Fc $\gamma$ and complement receptors: expression, role and co-operation in mediating the oxidative burst and degranulation of neutrophils of Brazilian systemic lupus erythematosus patients. Lupus 2002; 11: 240-8.

[36] Polhill RB Jr, Pruitt KM, Johnston RB Jr. Cinetic assessment of alternative complement pathway in a hemolytic system. I: experimental and mathematical analysis. J Immunol 1978; 121: 363-70.

[37] Boyden S. The chemotactic effect of mixtures of antibody and antigen on polymorphonuclear leukocytes. J Exp Med 1962; 15: 453-66.

[38] Zigmond SH, Hirsch JG. Leukocyte locomotion and chemotaxis: new methods for evaluation, and demonstration of a cellderived chemotactic factor. J Exp Med 1973; 137: 387-410.

[39] Thurman JM, Holers VM. The central role of the alternative complement pathway in human disease. J Immunol 2006; 176: 130510.

[40] Ji H, Ohmura K, Mahmood U, et al. Arthritis critically dependent on innate immune system players. Immunity 2002; 16(Suppl 2): 157-68.

[41] Banda NK, Thurman JM, Kraus D, et al. Alternative complement pathway activation is essential for inflammation and joint destruction in the passive transfer model of collagen-induced arthritis. J Immunol 2006; 177(Suppl 3): 1904-12.

[42] Lachmann PJ, Smith RA. Taking complement to the clinic--has the time finally come? Scand J Immunol 2009; 69(Suppl 6): 471-8.

[43] Holers VM. Complement. In: Rich R, Ed. Principles and practices of clinical immunology. St. Louis: Mosby 2001: 21.1-21.8.

[44] Holers VM. The complement system as a therapeutic target in autoimmunity. Clin Immunol 2003; 107: 140-51. 
[45] Woolley DE, Tetlow LC. Observations on the microenvironmental nature of cartilage degradation in rheumatoid arthritis. Ann Rheum Dis 1997; 56: 151-61.

[46] Solomon S, Kassahn D, Iiiges H. The role of the complement and the Fc $\gamma \mathrm{R}$ in the pathogenesis of arthritis. Arthritis Res Ther 2005; 7: 129-35.

[47] Belostocki K, Park MS, Redecha PB. FcgammaRIIa is a target for modulation by TNFalpha in human neutrophils. Clin Immunol 2005; 117: 78-86.

[48] Boross P, Verbeek JS. The complex role of Fc $\gamma$ receptors in the pathology of arthritis. Springer Semin Immun 2006; 28: 339-50.

[49] Weisman HF, Bartow T, Leppo MK, et al. Soluble human complement receptor type 1: in vivo inhibitor of complement suppressing post-ischemic myocardial inflammation and necrosis. Science 1990; 249(Suppl 4965): 146-51.

[50] Dreja H, Annenkov A, Chernajovsky Y. Soluble complement receptor 1 (CD35) delivered by retrovirally infected syngeneic cells or by naked DNA injection prevents the progression of collageninduced arthritis. Arthritis Rheum 2000; 43: 1698-709.

[51] Fearon DT. Regulation of the amplification C3 convertase of human complement by an inhibitory protein isolated from human erythrocyte membrane. Proc Natl Acad Sci USA 1979; 76(Suppl 11): 5867-71.

[52] Jarvis JN, Iobidze M, Taylor $\mathrm{H}$, et al. A comparison of immunoglobulin G-containing high-molecular-weight complexes isolated from children with juvenile rheumatoid arthritis and congenital human immunodeficiency virus infection. Pediatr Res 1993; 34(Suppl 6): 781-4.

[53] Lucisano YM, Lachmann PJ. The effect of antibody isotype and antigenic epitope density on the complement-fixing activity of immune complexes: a systematic study using chimaeric anti-NIP antibodies with human Fc regions. Clin Exp Immunol 1991; 84: 1-8.

[54] van Zeben D, Hazes JM, Zwinderman AH, et al. Clinical significance of rheumatoid factors in early rheumatoid arthritis: results of a follow up study. Ann Rheum Dis 1992; 51(Suppl 9): 1029-35.

(C) Paoliello-Paschoalato et al.; Licensee Bentham Open.

This is an open access article licensed under the terms of the Creative Commons Attribution Non-Commercial License (http://creativecommons.org/licenses/by-nc/3.0/) which permits unrestricted, non-commercial use, distribution and reproduction in any medium, provided the work is properly cited. 